\title{
Developing Assessment Framework for Strategic Transportation Projects in Qatar
}

\author{
Anas Mohammad \\ anas.mohammad@motc.gov.qa \\ Ministry of Transport and Communication, Doha, Qatar \\ Nabeel Al Rawi \\ nabeel.alrawi@motc.gov.qa \\ Ministry of Transport and Communication, Doha, Qatar \\ Osama Freija \\ osama.freija@motc.gov.qa \\ Ministry of Transport and Communication, Doha, Qatar
}

\begin{abstract}
This paper presents Transportation Assessment Framework and process for selecting, defining, and naming assessment criteria to be used in transport appraisal. The approach is based on a review of national and international practices in transportation planning and appraisal around the world but is adapted to attend the needs and particularities of the Qatar transportation system, according to Transportation Master Plan for Qatar (TMPQ) vision and objectives. The TMPQ vision is derived from four key strategic themes: development, sustainability, livability and culture. The outcome of the research is a comprehensive list, developed using this framework, of 37 transport assessment criteria encompassing direct project impacts, indirect societal impacts, and environmental impacts. This list can serve as a starting point for planners wishing to conduct appraisal for strategic transport projects. A Cost-Benefit Analysis (CBA) procedure and parameter are also developed as part of TAF for a more detailed assessment of the Preferred Scenario(s), covering the impacts (costs and benefits) which can be quantified and monetized. An Excel-based CBA tool is developed and applied to produce the main economic indicators for the preferred scenario, which form part of the assessment criteria that can be monetized.
\end{abstract}

Keywords: Transport; Master plan; Sustainability; Assessment; Framework

\section{INTRODUCTION}

The Transport Assessment Framework is developed to provide the overarching framework that recommends an integrated set of strategic transportation initiatives for all transportation modes across Qatar. The objectives of this paper is to present the development of Transport Assessment Framework (TAF) for the Transportation Master Plan for Qatar (TMPQ). The TAF sets out the methodology, approach, criteria, tools and parameters for the assessment of transportation plans, projects or schemes considered in the context of the TMPQ. The ultimate aim of the TAF process is to establish a consistent basis which enables the selection of schemes (or a combined set of schemes known as Scenario), based on the comparative assessment of alternative scenarios, resulting in an optimized solution which provides the greatest amount of benefits for the Qatari society as a whole. 
The TAF process will enable the comparative assessment of different scenarios developed to address future transportation provision for Qatar. Hence, it is intrinsically related to the definition of the vision and objectives for the TMPQ, ensuring that decisions are made in line with and to support the strategic vision and objectives. The TAF approach and procedures can be standardized for the assessment of any plan, project or scheme. It can also be customized to address the specific requirements of government agencies and private developers in Qatar in order to appraise their transportation and urban development schemes.

\section{REVIEW OF THE EXISTING NATIONAL TAF PRACTICES \& INTERNATIONAL BENCHMARKING}

The TAF approach is based on a review of national and international practices in transportation planning and appraisal around the world but is adapted to attend the needs and particularities of the Qatar transportation system, according to its specific vision and objectives.

\subsection{NATIONAL APPRAISAL PRACTICES FOR STRATEGIC TRANSPORT PLANNING}

This section presents an overview of the existing assessment frameworks and practices applied in recent transportation studies in Qatar.

Testing of Scenarios, Policies and Regulations report in the Transportation Master Plan for Qatar, (UPDA, 2008), set out three different transportation scenarios, combining highways, public transport and demand management measures. These scenarios were tested against a Do-Minimum scenario using WebTAG of the UK Department for Transport, along with the package tools such as the TUBA and CBA for a comprehensive economic appraisal. No specific framework had been developed for Qatar on that occasion. Expressway road program proposed the infrastructure improvements priorities were assessed using the Qatar Strategic Transport Model (QSTM), which provided the congestion index for each scenario under consideration. The congestion indices were used to compare the performance of the highway network between scenarios. Although this approach can be considered acceptable for the purposes of what was required at that time, this did not constitute a specific framework to be applied for all type of transportation projects.

In (MOTC, 2017), Qatar Bus Routes and Operations Study (QPROS), the development of the bus network was devised through the use of a bespoke Bus Planning Tool developed from QSTM, which allowed the testing of alternative scenarios. Once the optimum future bus network was agreed, supporting documentation was prepared including financial and implementation plans and the inputs for the business investment case. A Cost-Benefit Analysis (CBA) model was developed, whereby estimates for each scenario under consideration have been made for the Transport User Benefits (Passenger Hours); Total Fare Revenue (QAR); Depot and Stations Cost (QAR); Stops and Bus Priority Cost (QAR); Fleet Cost (QAR); and Operations and Maintenance Cost (QAR). All scenarios have been ranked on the basis of the respective Benefit Cost Ratios (BCRs). This is a standard approach for the assessment of monetized impacts of transportation projects, however it does not capture other important implications such as accessibility, 
emissions, accidents, fuel consumption, integration, security, urban realm and cultural norms.

\subsection{INTERNATIONAL BEST PRACTICES FOR STRATEGIC TRANSPORT APPRAISAL}

The benchmarking cities have been selected at previous stages of the TMPQ process. The international best practice review examined different approaches adopted elsewhere, which can be summarized as:

- Auckland, (NZ Transport Agency, 2015) - the approach adopted is an MCA focused on the prioritization of options but offers limited information about the estimating methods for the 28 indicators.

- Atlanta - the approach is based on an MCA and CBA process, which seems to be an appropriate way to structure the TAF.

- San Diego - the approach is also based on MCA and CBA tools.

- London - the approach used is that applicable to the entire UK, described by WebTAG. It contains a very comprehensive set of tools for modelling and appraisal, including a comprehensive CBA. The results of the appraisal process are helpfully summarized by Appraisal Summary Tables (AST).

- Abu Dhabi - the approach adopted is also based on an MCA, which includes economic and financial impacts.

\section{THE RECOMMENDED TAF DEVELOPMENT APPROACH}

The recommended approach for TAF development is based on a review of national and international practices in transportation planning and appraisal around the world, but is adapted to attend the needs and particularities of the Qatar transportation system, according to its specific vision and objectives. It also considers the vision and objectives for transportation system in Qatar. The TMPQ vision statement is derived from four key strategic themes: development, sustainability, livability and culture, as stated "An Integrated and Sustainable Transportation System that Supports the Economy and better Quality of Life while Preserving National Identity". The Table 2 below shows the general and specific objectives of the strategic transportation system in Qatar. The principles underlying the conception of TAF are:

- Multimodal approach: A multimodal network planning approach focused on meeting people's mobility needs and freight transportation users' requirements. Strategic transportation planning and investment decisions must be made from an integrated multimodal perspective, whereby TAF enables the assessment of schemes from all modes as well as a combination or package of schemes from different modes.

- Holistic perspective: It is important to account for the interaction between land use and transportation planning, bringing together economic, social and environmental considerations. TAF also needs to complement and enhance existing assessment practices in Qatar. In addition, TAF needs to incorporate a way of measuring or qualifying the effects of soft transportation initiatives, such as policies, regulations and governance.

- Integration of stakeholder requirements and contributions: Relevant stakeholder requirements play an important role throughout the TAF development. A joint 
approach between the national government administrations involved in the planning, regulation or provision of transportation services should be adopted to facilitate the decision-making process.

- Objective-led and responsive: The development and assessment of schemes or plans must be driven by strategic and specific objectives, so that outcomes are aligned with the wider vision and objectives for transportation in Qatar, and be responsive to address the identified challenges in the transportation system.

- Transparent and unbiased process: The guidance should be structured, standardized, transparent, objective and unbiased, supported by both quantitative data and qualitative information, to ensure consistency in the assessment and inspire confidence in the process.

- Broad applicability: TAF needs to be suitable to be applied to a wide range of land use and transportation projects, of different natures (i.e. infrastructure, services, and facilities), sizes and at different stages of development, from strategic planning to feasibility.

- Ease of understanding: TAF guidelines should be implementable by various government and private organizations, hence need to be clear, specific and descriptive. Results must be presented in a way that is easily understandable to professionals outside the transportation planning field and to the general public.

\section{THE TAF PROCESS \& PROCEDURES}

TAF has a role over different parts of the developing transport scheme/scenarios, as illustrated in the following Figure.

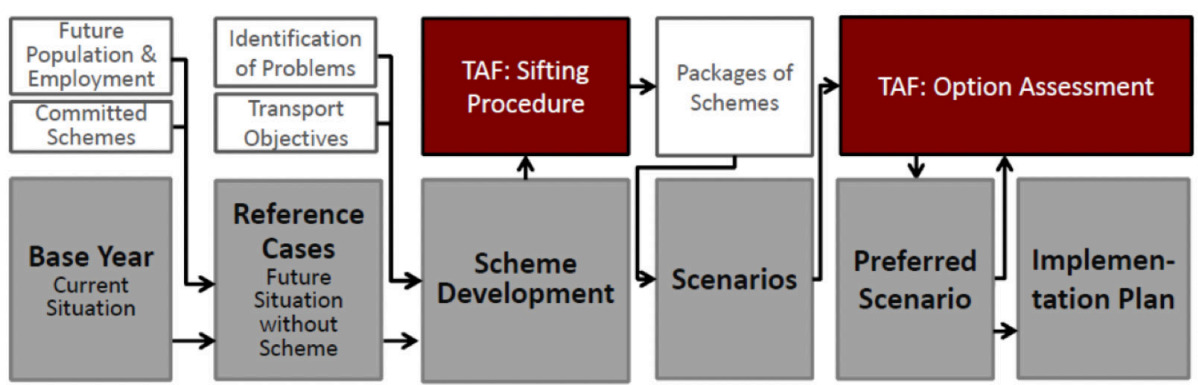

Figure 1: The Role of the TAF in the Transport Schemes Development Process (TMPQ, 2020)

\subsection{Scheme Development}

This step produces a range of transportation solutions for all modes, which has to be identified to address existing transport challenges and future mobility requirements, as well as to improve efficiency, reliability, safety or reduce congestion and externalities such as pollution and fuel consumption. A long list of proposed schemes/options (including physical measures and policy interventions) shall be developed, considering schemes proposed by stakeholders, government agencies, private developers and a wide range of other initiatives put forward for consideration. These schemes/options have to be developed to a level that enables them, where possible, to be tested, quantified, mapped, costed and simulated using the strategic transportation model (if applicable). 
The following information shall be reported about each scheme i.e. description, metrics, mode type, classification, scheme objective, challenges, source, feasibility, risk ...etc.

\subsection{The Sifting Procedure}

TAF has a role in "Scheme Development" by establishing a set of sifting criteria used to narrow down an initial long list of options, actions, measures, initiatives and policies into a more focused (or short) list of schemes to be further tested, refined and assessed as illustrated in below Figure. It also provides a framework for the analysis of the alignment of the proposed schemes against the specific objectives of the TMPQ, which is one of the sifting criteria. This procedure is essentially a qualitative process based on professional judgement and a certain degree of subjectivity.

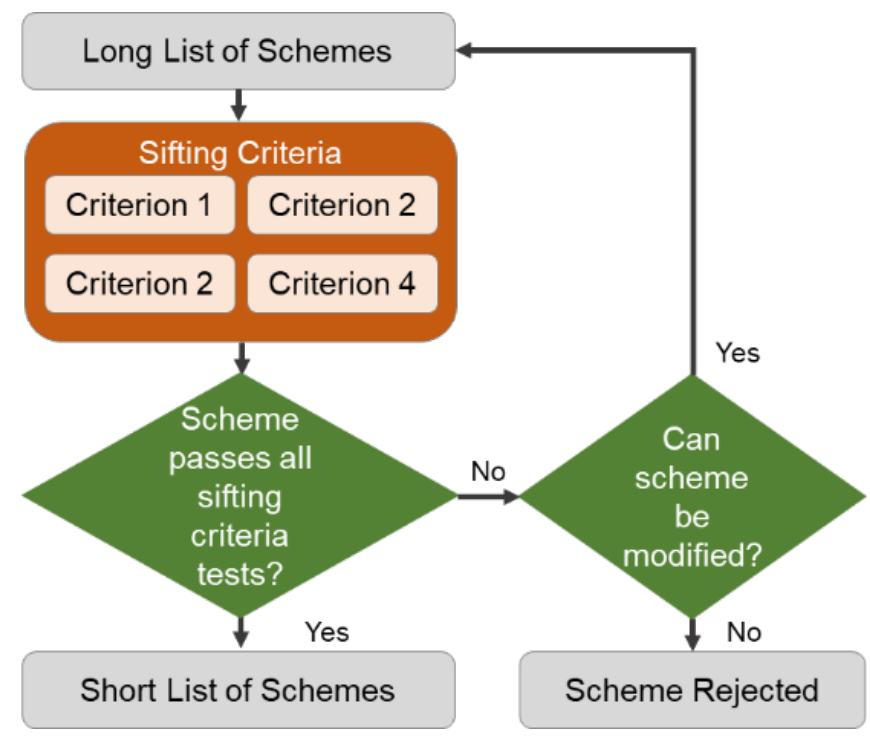

Figure 2: The Sifting Procedure (TMPQ, 2020)

The proposed FOUR sifting criteria are as follows:

a) Criteria No. 1: Schemes that are outside the sphere of analysis and intervention, or outside the scope of the land transport, would not qualify for progressing to the next stage of assessment:

- Schemes are related to air transport and airports, other than their accesses and connections with the surface transportation network;

- Schemes are related to maritime transportation and interventions in ports, other than their accesses and connections with the surface transportation network, except those involving the development of infrastructures and facilities for the provision of maritime bus and taxi services between different parts of the country;

- Schemes are related with transportation by ducts and pipelines; or

- Schemes are related to logistics and freight facilities or logistic centers, other than their accesses and connections with the surface transportation network.

b) Criteria No. 2: Schemes that are not sufficiently aligned with the specific objectives for the transportation system, would not qualify for progressing to the next stage of 
assessment. This sifting criterion verifies the extent to which each scheme is capable of enhancing the performance of the transport network under at least one of the specific objectives of TAF. Qualitative (or more subjective) assessments have been made using on a five-point scale intended to measure the comparative magnitude and direction of the impact assessed against each specific objective. Table below shows the ranking used to test the qualitative alignment of scheme impacts against the objectives of the transport system.

Table 1: Qualitative Scheme Assessment against the Specific Objectives (TMPQ, 2020)

\begin{tabular}{|l|l|c|}
\hline Assessment & Description & Points (Scale) \\
\hline HIGHLY POSITIVE & The scheme has a significantly beneficial impact in relation to a specific objective & +2 \\
\hline POSITIVE & The scheme has a slightly beneficial impact in relation to a specific objective & +1 \\
\hline NEUTRAL & The scheme has no significant impact in relation to a specific objective & 0 \\
\hline NEGATIVE & The scheme has a slightly adverse impact in relation to a specific objective & -1 \\
\hline HIGHLY NEGATIVE & The scheme has a significantly adverse impact in relation to a specific objective & -2 \\
\hline
\end{tabular}

c) Criteria No. 3 "FEASIBILITY, RISK AND ACCEPTABILITY": Under this sifting criterion, schemes that are considered not technically or environmentally feasible or which reveal a high risk of implementation should need to be reconsidered or rejected. This might be the case of proposals involving, for instance:

- The implementation of untested transportation solutions with high technological and regulatory risks;

- A level of investment that is significantly disproportional or not possibly justifiable in relation to expected social benefits or levels of patronage; or

- A severe degree of objection that can be expected from members of the public, government agencies or other stakeholders.

d) Criteria No. 3 "REDUNDANCY OR BETTER COVERED BY OTHER SCHEMES": Schemes which can be considered redundant for being more appropriately covered or more effectively addressed by any other more relevant schemes may be removed from consideration, subject to convincing explanations and reasoning being provided. The aim is to remove solutions which are the not most suitable for the local conditions in Qatar or which would overlap in scope, geography or aims with other more pertinent solutions.

\subsection{Scenario Development}

The schemes shall be grouped into coherent packages, or scenarios. Accordingly, numerous or endless combination of schemes can be developed. Therefore, in order to identify the group of schemes to be included for next step of scenarios assessment, a prioritization exercise needs to be carried out, evaluating the schemes against a set of criteria. The criteria used for this exercise for highway and public transport are summarized in below Table. 
Table 2: Evaluation Criteria for Highway and Public Transport Schemes (TMPQ, 2020)

\begin{tabular}{|l|l|}
\hline Mode & Criteria \\
\hline \multirow{5}{*}{ Highway } & Connectivity to new developments \\
\cline { 2 - 3 } & Dependency on other schemes \\
\cline { 2 - 2 } & Level of service (V/C) \\
\cline { 2 - 3 } & Traffic volume served by the scheme \\
\cline { 2 - 2 } & Total vehicle-km \\
\cline { 2 - 2 } & Strategic routes \\
\cline { 2 - 2 } & $\begin{array}{l}\text { Connectivity to major developments, key locations } \\
\text { and centers }\end{array}$ \\
\cline { 2 - 2 } & Support for truck movements \\
\cline { 2 - 2 } & Alignment against planning objectives \\
\hline & Dependency on other schemes \\
\cline { 2 - 2 } & Level of service (V/C) \\
\cline { 2 - 2 } & Population / employment catchment \\
\cline { 2 - 2 } & $\begin{array}{l}\text { Connectivity to major developments, key locations } \\
\text { and centers }\end{array}$ \\
\cline { 2 - 2 } & Ridership (PT passenger volume) \\
\cline { 2 - 3 } & Total passenger-km \\
\cline { 2 - 2 } & Alignment against planning objectives \\
\hline
\end{tabular}

\subsection{The Scenario/Options Assessment}

Once the Scheme successfully passed the sifting procedure and added to the focused (or short) list of schemes. In the context of the TMPQ, these options will effectively be the future transportation scenarios. Hence, the assessment will be carried out in aggregate terms for the impacts of each scenario, which comprise different integrated and coherent packages of schemes combined.

This stage of TAF uses a standardized multi-criteria assessment (MCA), which is tailored for the purposes and objectives of the TMPQ, for the scenarios/options assessment. This section defines the scope, criteria, and level of analysis required for the assessment of any transportation interventions in Qatar. The assessment of future options/scenarios will be made by comparisons of their impacts ("With Schemes") against the Reference Case ("Without Schemes") for the ultimate horizon year (2050). A comprehensive range of qualitative and quantitative assessment indicators were developed which is illustrated as an Appraisal Summary Table (AST). The AST facilitates the presentation of the impacts from different scenarios using a standard format, which will support and facilitate decision making on the selection of the preferred scenario as shown in the Figure below (Figure 3).

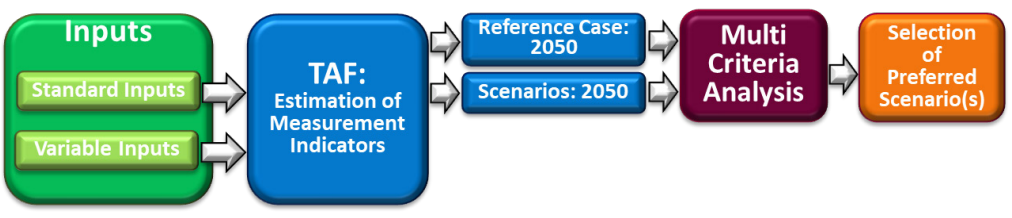

Figure 3: The MCA Process within TAF (TMPQ, 2020) 
Table below presents the AST which includes a summary of the assessment of several indicators that were defined based on the possible ways of measuring the degree of fulfilment of the specific objectives of the transport system in Qatar. Individually, each indicator can only provide an indication of an aspect or a perspective for a specific impact, but collectively these indicators have been developed to represent a meaningful and sufficiently robust assessment framework. The ASTs ensure that the differences in performance between the alternative transportation scenarios can be clearly identified. Their standardized format provides ease of understanding and interpretation by decision makers. Whenever possible, the assessment indicators have been defined by transportation mode, by passenger/freight or by any other relevant classification and also how each indicator is expected to be measured, if quantitatively by either the QSTM, by other means (e.g. GIS) or by estimates made without the use of the model) or qualitatively.

MOTC developed a full description for the required data (variables, assumptions and standard inputs or parameters) and the methodology for the estimation of the proposed assessment indicators used to evaluate the contribution of alternative scenarios towards achieving each specific objective mentioned earlier.

The assessment of qualitative indicators is made by qualitative statements with a description the extent to which proposed measures within the scenario evaluated are expected to impact. A five-point scoring scale defining the degree of its contribution will be produced in order to compare the impacts between scenarios in the same way as used in the alignment of schemes against objectives, described in Table 2 in section 4.1. The AST does not identify the relative importance of the various objectives, indicators and associated impacts. This subjective aspect regarding the weighting between objectives and indicators is left to decision makers, with the AST only representing a summary of the expected set of impacts.

\subsection{Cost Benefit Analysis}

Cost-benefit analysis (CBA) is a process used to analyze decisions, whereby costs and benefits of an option/scenario are converted into the same monetary basis and added up to reflect the overall impact, highlighting the overall balance between costs and benefits. Such normalization of impacts measured in monetary units allows for better informed decision-making. Costs will include items such as capital expenditures and the annual operating and maintenance costs. Benefits will include revenues together with a monetized estimation of the social impacts accrued to users and non-users such as journey time savings, vehicle operating cost savings, monetary valuation of changes in emissions (by pollutant) and fuel consumption and monetary valuation of changes in traffic accidents (by severity type). A CBA for Qatar was developed to be applied to the Scheme/Scenario(s), for which assessment results are required for all horizon years. The CBA components include input and parameters such as Capital expenditures; Optimism bias; Annual operating and maintenance costs; Revenues from public transport fares, tolls and parking; User benefits (Travel time savings; and Vehicle operating cost savings), Non-User benefits (Changes in emissions and fuel consumption; Changes in energy consumption; and Changes in traffic accidents). The parameters of CBA and input values described above were developed based on existing data and a research market. The outcome of CBA using this tool will assist the calculation of Benefit-Cost Ratio, Net 
Present Value and Internal Rate of Return.

Table 3: AST Measurement Indicators for Scenario/Option Assessment (TMPQ, 2020)

\begin{tabular}{|c|c|c|c|c|c|}
\hline \multirow[b]{2}{*}{$\begin{array}{l}\text { General } \\
\text { objectives }\end{array}$} & \multirow[b]{2}{*}{ Specific Objectives } & \multirow[b]{2}{*}{ Measurement Indicator (Changes in Relation to the Reference Case) } & \multicolumn{3}{|c|}{ Measurement Type } \\
\hline & & & 殸 & 递 & \\
\hline \multirow{6}{*}{$\begin{array}{l}\text { 1. Provide an } \\
\text { Efficient \& } \\
\text { integrated } \\
\text { Transportation } \\
\text { System }\end{array}$} & $\begin{array}{l}\text { 1.1. Improve Operational Efficiency of the } \\
\text { Transportation System }\end{array}$ & $\begin{array}{l}\text { Total distance traveled by mode (vehicle-km/year) } \\
\text { Average passenger travel distance by mode }(\mathrm{km} / \mathrm{journey}) \\
\text { Average passenger travel speed by mode }(\mathrm{km} / \mathrm{h})\end{array}$ & $\checkmark$ & & \\
\hline & $\begin{array}{l}\text { 1.2. Reduce the Amount of Time Spent by } \\
\text { Passengers Traveling }\end{array}$ & $\begin{array}{l}\text { Total pass-h by mode (pass-hours/year) } \\
\text { Average journey time by mode (minutes/journey) }\end{array}$ & $\checkmark$ & & \\
\hline & 1.3. Seek Reliable Movement of Goods & $\begin{array}{l}\text { Number of goods vehicle hours under congested and uncongested conditions (\# hours) } \\
\text { Percentage of goods vehicle hours under congested conditions over the total hours traveled (\%) }\end{array}$ & $\checkmark$ & & \\
\hline & 1.4. Seek Reliable Movement for Travelers & $\begin{array}{l}\text { Number of passenger-hours under congested and uncongested conditions for road vehicles (\# hours) } \\
\text { Percentage of passenger-hours under congested conditions over the total passenger-hours (\%) }\end{array}$ & $\checkmark$ & & \\
\hline & \multirow{2}{*}{$\begin{array}{l}\text { 1.5. Improve Integration Between Different Services } \\
\text { and Modes }\end{array}$} & $\begin{array}{l}\text { Number of trips and average number of trips that entail } \geq 1 \text { transfers (\#) } \\
\text { Average time spent in transfers (hours) }\end{array}$ & $\checkmark$ & & \\
\hline & & $\begin{array}{l}\text { Qualitative statements that summarize the extent to which proposed measures are expected to impact in overall levels of } \\
\text { network integration between services and modes (both physical improvements and policy-based improvements) }\end{array}$ & & & $\checkmark$ \\
\hline \multirow{7}{*}{$\begin{array}{l}\text { 2. Promote } \\
\text { Transportation } \\
\text { Mobility \& } \\
\text { Accessibility }\end{array}$} & \multirow{2}{*}{$\begin{array}{l}\text { 2.1. Increase the Availability and Attractiveness of } \\
\text { Public Transport }\end{array}$} & Market share of Public Transport by mode (\%) & $\checkmark$ & & \\
\hline & & Population within a certain distance of a PT service (number of residents) & & $\checkmark$ & \\
\hline & 2.2. Improve Access to Essential Destinations & Accessibility index to employment, health and education destinations by car and Public Transport (index) & & $\checkmark$ & \\
\hline & $\begin{array}{l}\text { 2.3. Provide an Affordable Transportation } \\
\text { Experience }\end{array}$ & $\begin{array}{l}\text { Average journey cost by mode (QAR/journey) } \\
\text { Market share of the different modes per population group / level of income (\%) }\end{array}$ & $\checkmark$ & & \\
\hline & \multirow{2}{*}{ 2.4. Improve Non-Motorized Mobility Options } & $\begin{array}{l}\text { Number of trips made by walking \& cycling (\#) } \\
\text { Percentage of trips made by walking \& cycling }(\%)\end{array}$ & $\checkmark$ & & \\
\hline & & $\begin{array}{l}\text { Pedestrian and Cycling Activity - qualitative statements that summarize the understanding of the scale and impact of any } \\
\text { pedestrian and cycle related improvements }\end{array}$ & & & $\checkmark$ \\
\hline & $\begin{array}{l}\text { 2.5. Ensure Acceptable Travel Conditions by all } \\
\text { Modes for all Travelers }\end{array}$ & $\begin{array}{l}\text { Levels of Service on all modes (roads and public transport): } \\
\text { - For roads: Km of network operating under different Levels of Service }(\mathrm{km}) \\
\text { For PT: } \mathrm{km} \text { of } \mathrm{PT} \text { network operating under different Levels of Service }(\mathrm{km})\end{array}$ & $\checkmark$ & & \\
\hline \multirow{2}{*}{$\begin{array}{l}\text { 3. Ensure a } \\
\text { Safe \& Secure } \\
\text { Transportation } \\
\text { System }\end{array}$} & 3.1. Reduce Number and Severity of Accidents & Number of expected accidents: total number of accidents by level of severity and road type (number of accidents) & $\checkmark$ & $\checkmark$ & \\
\hline & 3.2. Ensure Safe and Secure Transportation System & $\begin{array}{l}\text { Qualitative statements that summarize how security and/or personal safety is anticipated to be improved by the proposed } \\
\text { measures included in each alternative scenario. }\end{array}$ & & & $\checkmark$ \\
\hline \multirow{2}{*}{$\begin{array}{l}\text { 4. Protect the } \\
\text { Environment } \\
\text { \& Ensure } \\
\text { Sustainable } \\
\text { Development }\end{array}$} & $\begin{array}{l}\text { 44.1. Reduce Transportation Related Local \& Global } \\
\text { Emissions }\end{array}$ & Estimation of the annual quantities of $\mathrm{CO}_{2}, \mathrm{NO}_{x}, \mathrm{CO}, \mathrm{HC}$, PM emissions (tones/year) & $\checkmark$ & $\checkmark$ & \\
\hline & $\begin{array}{l}\text { 4.2. Enhance Transportation Energy and fuel } \\
\text { Efficiency }\end{array}$ & $\begin{array}{l}\text { Estimation of the annual fuel consumption by mode (liters/year) } \\
\text { Estimation of the annual energy consumption by mode (megajoules/year) }\end{array}$ & $\checkmark$ & $\checkmark$ & \\
\hline
\end{tabular}

\begin{tabular}{|c|c|c|c|c|c|}
\hline \multirow[b]{2}{*}{$\begin{array}{l}\text { General } \\
\text { objectives }\end{array}$} & \multirow[b]{2}{*}{ Specific Objectives } & \multirow[b]{2}{*}{ Measurement Indicator (Changes in Relation to the Reference Case) } & \multicolumn{3}{|c|}{ Measurement Type } \\
\hline & & & 憵 & 蛋 & \\
\hline & 4.4. Ensure Sustainable Development & $\begin{array}{l}\text { Qualitative statements that summarize the extent to which the proposed measures scheduled in each alternative scenario would } \\
\text { contribute to encouraging sustainable development. }\end{array}$ & & & 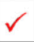 \\
\hline \multirow{3}{*}{$\begin{array}{l}\text { 5. Support } \\
\text { Economic } \\
\text { Development }\end{array}$} & 5.1. Improve Access to the Workforce & $\begin{array}{l}\text { Number of employees located within a predetermined travel time catchment, by private vehicles and public transport, for } \\
\text { selected employment locations }(\#)\end{array}$ & $\checkmark$ & $\checkmark$ & \\
\hline & 5.3. Improve the Travel Experience for Tourists & $\begin{array}{l}\begin{array}{l}\text { Average travel times between main tourist O-D pairs (tourist attractions, hotel areas, HIA, Doha and Hamad Ports) by taxi and PT } \\
\text { (minutes/journey) } \\
\text { Average travel costs between main tourist O-D pairs (tourist attractions, hotel areas, HIA, Doha and Hamad Ports) by taxi and PT } \\
\text { (QAR/journey) }\end{array}\end{array}$ & $\checkmark$ & & \\
\hline & $\begin{array}{l}\text { 5.4. Improve Integration between Transportation \& } \\
\text { Land Use Planning }\end{array}$ & $\begin{array}{l}\text { Qualitative statements that summarize the extent to which integration between the transportation system and land use will be } \\
\text { improved and the impacts this may have in generating additional economic activity }\end{array}$ & & & $\checkmark$ \\
\hline
\end{tabular}

\section{CONCLUSION}

This paper presented the Transportation Appraisal Framework (TAF) development and stages in Qatar, which has been conceived for the purposes of transport schemes option/scenario assessment within the TMPQ. It sets out the parameters and methodology for the assessment of options, which can also be used for the assessment of any other transportation intervention requiring approval and/or funding in Qatar to provide the greatest amount of sustainable benefits for the Qatari society as a whole. This paper makes three practicable contributions: 
1. A framework for systematically defining and naming assessment criteria to be used as a consistent basis of the comparative assessment of alternative scenarios,

2. A viable list of AST criteria that is readily applicable to all transport projects.

3. A clear procedure and process to use TAF for developing and assessing transport scheme/scenarios.

Developed TAF in Qatar is a form of Multi-Criteria Assessment (MCA), which in this case is structured into 6 General Objectives, 22 Specific Objectives plus the CBA, with a total of 37 indicators in addition to those economic and financial indicators from the CBA. The results of the MCA for each scenario are summarized in the Appraisal Summary Table (AST) in relation to the "without project" situation (Reference Case). The trade-offs between the various assessment indicators for each scenario/option under consideration are used for the analysis of the comparative performances of the different scenarios with the objective of supporting decision-making. The implementation of TAF and CBA is undertaken by MOTC.

The ultimate outcome of scenario/option assessment is the selection of the preferred scenario/option, which will be that representing the highest amount of benefits for Qatar, taking into account the trade-offs between a wide range of impacts for each scenario on transportation objectives and the corresponding costs and risks.

\section{REFERENCES}

Auckland Regional Land Transport Plan 2015-2025 (RLTP), NZ Transport Agency, Kiwi Rail, Auckland Council and Auckland Transport. Retrieved from: https://at.govt.nz/media/1191335/ Regional-Land-Transport-Plan-Adopted-Version-July-2015.pdf.

Qatar Bus Routes and Operations Study (QBROS) (2017). MOTC.

Qatar Strategic Transport Model v2.0, VISUM (2018). MOTC.

Transportation Master Plan for Qatar (TMPQ) (2008). Urban Planning \& Development Authority (UPDA).

Transportation Master Plan for Qatar (TMPQ) (2020). Ministry of Transport and Communication (MOTC).

WebTAG, Transport analysis guidance (TAG) (2013). UK Department for Transport. Retrieved from: https://www.gov.uk/guidance/transport-analysis-guidance-webtag. 